\title{
Safety, tolerability, and pharmacokinetics of
} simotinib, a novel specific EGFR tyrosine kinase inhibitor, in patients with advanced non-small cell lung cancer: results of a phase lb trial

This article was published in the following Dove Press journal:

Cancer Management and Research

\author{
Xing-Sheng $\mathrm{Hu}^{1}{ }^{1} *$ \\ Xiao-Hong $\operatorname{Han}^{1,2, *}$ \\ Sheng Yang \\ Ning $\mathrm{Li}^{1}$ \\ Lin Wang \\ Yuan-Yuan Song' \\ Hua $\mathrm{Mu}^{3}$ \\ Yuan-Kai Shi ${ }^{1}$ \\ 'Department of Medical Oncology, \\ Beijing Key Laboratory of Clinical Study \\ on Anticancer Molecular Targeted Drugs, \\ National Cancer Center/National Clinical \\ Research Center for Cancer/Cancer \\ Hospital, Chinese Academy of Medical \\ Sciences \& Peking Union Medical College, \\ Beijing, People's Republic of China; \\ ${ }^{2}$ Department of Clinical Laboratory, \\ National Cancer Center/National Clinical \\ Research Center for Cancer/Cancer \\ Hospital, Chinese Academy of Medical \\ Sciences \& Peking Union Medical College, \\ Beijing, People's Republic of China; \\ ${ }^{3}$ Simcere Pharmaceutical Group, Nanjing, \\ People's Republic of China
}

*These authors contributed equally to this work

Correspondence: Yuan-kai Shi Department of Medical Oncology, Beijing Key Laboratory of Clinical Study on Anticancer Molecular Targeted Drugs, National Cancer Center/National Clinical Research Center for Cancer/Cancer Hospital, Chinese Academy of Medical Sciences \& Peking Union Medical College, Beijing I0002I, People's Republic of China

Tel +86 1087788293

Fax +86 1087778740

Email syuankai@cicams.ac.cn
Purpose: The aim of this phase Ib study (clinicaltrials.gov: NCT01772732) was to assess safety, tolerability, and pharmacokinetics (PKs) of simotinib (a novel EGFR tyrosine kinase inhibitor) in patients with advanced non-small cell lung cancer (NSCLC) and EGFR gene mutation.

Patients and methods: 41 patients with $E G F R$ gene mutations were enrolled and received simotinib orally administered twice daily with dose escalating from 100 to $650 \mathrm{mg}$ in 28 days cycle. Safety and tolerability were assessed through the study. Blood samples were collected for PK analysis on Days 1, 8, 9, 10, 15, 22 and 29. Tumor response was assessed at baseline, on Day 29 and every 8 weeks thereafter.

Results: Simotinib was well tolerated, with no dose-limiting toxicities. Maximum tolerated dose (MTD) was not found. $95.1 \%$ of patients experienced at least one adverse event (AE), and most of them were mild or moderate. Rash (41.5\%) and diarrhea (56.1\%) were the most frequently reported AEs. Simotinib was rapidly absorbed and eliminated with average $T_{\max }$ ranging from 1 to $4 \mathrm{hrs}$ and $T_{1 / 2}$ ranging between 6.2 and $13.0 \mathrm{hrs}$ after multiple-dose administration. No dose-response relationship between dose and exposure was observed after multiple-dose administration. $39.3 \%$ of the enrolled patients achieved a partial response and $46.3 \%$ had stable disease. Median progression-free survival and overall survival were 9.9 (CI\% 4.7; 12.1) months and 14.6 (95\%CI 12.3; 22.5) months, respectively.

Conclusion: Simotinib was well tolerated, with manageable AEs at doses of up to $650 \mathrm{mg}$ and MTD was not reached. Further studies to explore higher doses are ongoing.

Keywords: simotinib, EGFR, non-small cell lung cancer, toxicity, pharmacokinetics

\section{Introduction}

Worldwide lung cancer remains one of the leading causes of cancer-related deaths. In 2012, it was responsible for $19.4 \%$ (1.6 million) of all deaths due to cancer. ${ }^{1}$ Non-small cell lung cancer (NSCLC) represents up to $87.0 \%$ of the total lung cancer cases, is associated with 30-40\% 1-year net survival rate, and many patients are diagnosed with advanced disease due to its insidious onset. ${ }^{2,3}$ Despite introduction of molecular-targeted therapies and histology-based cytotoxic chemotherapy, the survival of these patients is limited. ${ }^{4}$

EGFRs are highly expressed in a number of human tumors and are associated with poor prognosis. ${ }^{5}$ In patients with NSCLC, the overall reported prevalence of EGFR-gene mutations is $33.1 \%$, with higher prevalence in women, Asian populations (India, China, 
Japan and Taiwan), non-smokers and in those with adenocarcinoma. ${ }^{6}$ Also, their presence is associated with significantly longer survival of these patients as compared to EGFR wild type (13.3 vs 30.9 months, $P<0.001) .{ }^{4}$ The introduction of EGFR tyrosine kinase inhibitors (EGFR-TKIs) in the therapy of NSCLC has been an important step-forward with significant clinical benefit especially in those harboring EGFR mutations. ${ }^{7-11}$

Simotinib (Simcere Pharmaceutical Group, Nanjing, China) is a novel selective and specific TKI acting through inhibition of EGFR tyrosine kinase activity which showed favorable tolerability profile in preclinical studies. ${ }^{12,13}$ In vitro studies showed that simotinib inhibits in a dosedependent manner EGFR and the growth of human A431 tumor cells with high expression of EGFR, with no significant activity on other investigated kinases. ${ }^{12}$ It has a half maximal inhibitory concentration of $19.9 \mathrm{nM}$ on EGFR. In vivo, simotinib has been shown to exert its antitumor activity by inhibiting EGFR phosphorylation in nude xenograft model. Preclinical toxicology studies demonstrated that simotinib has a favorable tolerability. The common toxicities include weight loss, diarrhea, salivation, and alopecia. Our previous phase Ia study in 12 healthy volunteers showed that simotinib was well tolerated and had an average clearance (CL) $T_{1 / 2}$ of 8-12 hrs in the dose range of $25-500 \mathrm{mg}$, suggesting that twice-daily administration is recommended. ${ }^{12}$

Here, we report the results of a phase Ib study with the primary objective to investigate the safety and tolerability of multiple ascending doses of simotinib in patients with advanced NSCLC and EGFR gene mutations. Secondary objectives were to evaluate the pharmacokinetic (PK) profile and to explore the preliminary anti-tumor activity of simotinib in these patients.

\section{Material and methods}

\section{Study design and treatment}

This was a single center, non-randomized, dose escalation phase Ib study performed between April 2013 and July 2015 in National Cancer Center/Cancer Hospital, Chinese Academy of Medical Sciences and Peking Union Medical College Beijing, China (clinicaltrials. gov: NCT01772732). Eligible patients were sequentially assigned to receive a cycle of simotinib (flat doses of $100,200,300,400,500$, and $650 \mathrm{mg}$, respectively) following a $3+3$ dose escalation design according to a modified Fibonacci scheme. Simotinib was orally administered twice per day for 28 days (treatment phase); no other chemotherapy regimens were allowed during the study. After the completion of the enrollment procedure, patients were assigned to receive one of the studied doses and continued with the assigned dose during the treatment period. Enrollment of patients in subsequently higher dose level group, and thus dose escalation, begun only if no dose-limiting toxicity (DLT) was observed in any of the treated patients in the lower dose level group during the 28-day treatment period. The maximum tolerated dose (MTD) was considered as reached, and thus defined, if $>1$ patient developed DLT at any dose level.

Simotinib was manufactured by Simcere Pharmaceutical Group and was packed and labeled by the manufacturer which was also the study sponsor.

Following the screening/enrollment visit, during the treatment phase, each patient underwent 7 study evaluations on Days 1 (first study drug administration), 8, 9, 10, 15,22 , and 29. During these visits, samples were collected for PK analysis. After the treatment phase, patients were followed, every 8 weeks until disease progression, death, or study termination. Safety and toxicity were collected through the study. Tumor evaluation was performed by imaging techniques (computed tomography [CT] or magnetic resonance imaging) at study enrollment (Baseline), on Day 29 and every 8 weeks thereafter.

\section{Study population}

Adult patients at $18-65$ years of age, with histologically confirmed advanced NSCLC with $E G F R$ gene mutations (E19del, L858R, L861Q, G719X, etc.) and relapsed following therapy with at least one platinum-based regimens were enrolled. Additionally, to be eligible patients had to have an Eastern Cooperative Oncology Group (ECOG) performance status between 0 and 2, an estimated life expectancy $\geq 12$ weeks, adequate bone marrow, liver and renal functions (absolute neutrophil count $\geq 1.5 \times 10^{9} / \mathrm{L}$, platelet count $\geq 80 \times 10^{9} / \mathrm{L}$, hemoglobin value $\geq 90 \mathrm{~g} / \mathrm{L}$, serum bilirubin $<2 \times U N L$, liver transaminase levels $\leq 2 \times \mathrm{UNL}$ or $\leq 5 \times \mathrm{UNL}$ if liver metastasis, estimated creatinine $\mathrm{CL} \geq 60 \mathrm{~mL} / \mathrm{min}$ or serum creatinine levels $\leq 1.5 \times \mathrm{UNL}$ ). Women of childbearing potential had to have a negative pregnancy test within 7 days prior to treatment start and had to use an approved contraceptive method during the study; men were enrolled if they were surgically sterile or agreed to use an approved contraceptive method during the study. 
Exclusion criteria included evidence of interstitial lung disease, idiopathic pulmonary fibrosis identified by CT examination performed at baseline; left ventricular ejection fraction (LVEF) $<50 \%$; central nervous system metastasis recently diagnosed which had not been treated by surgery or radiotherapy; previous therapy with EGFRTKIs or other relevant molecular targeted drugs; treatment with rifampin, rifabutin, rifapentine, dexamethasone, phenytoin sodium, carbamazepine, phenobarbital, Hypericum perforatum, atazanavir, clarithromycin, indinavir, itraconazole, ketoconazole, nefazodone, nelfinavir, ritonavir, saquinavir, or telithromycin at study enrollment; any unstable systemic disorders (including active infection, uncontrollable hypertension, unstable angina pectoris, congestive heart failure, liver and kidney disorders or metabolism disease); other malignancies diagnosed within the last 5 years with the exception of completely cured cervical cancer in situ, or basal and squamous cell skin cancer; history of neurologic or psychiatric disorders, including epilepsy or dementia.

\section{Assessment of safety and toxicity}

Safety analyses, the primary outcome of this study, were performed in the safety population, which included all patients who received at least one dose of simotinib.

During the study, adverse events (AEs), serious adverse events (SAEs), and hematological toxicity by general physical examination, special examinations (chest $\mathrm{X}$-ray, electrocardiogram, echocardiography) and laboratory investigations were collected. Blood samples for safety laboratory investigations were collected on Days $1,8,15,22$ and 29, before study drug administration and included hematological assessment, and assessment of liver and renal functions. Toxicities were described and graded according to the National Cancer Institute Common Terminology Criteria for Adverse Events (NCI CTC AE) version 4.0.

DLT was defined as any of the following drug-related AEs: blood pressure $>150 / 100 \mathrm{mmHg}$ that could not be controlled with medication; a decrease of the LVEF $>10 \%$ or symptoms suggestive for cardiac dysfunction; grade 4 diarrhea or grade 3 diarrhea twice a day or with a duration longer than $24 \mathrm{hrs}$, or diarrhea treated with active medication (loperamide and intravenous fluid replacement were permitted); vomiting grade 3 which could not be controlled by active treatment; renal toxicity $\geq$ grade 2 ; liver toxicity $\geq$ grade 3; rate-corrected QT interval (QTc) $\geq 500 \mathrm{~ms}$; severe rash or other skin disorders which could not be controlled by therapy, or with a duration over 2 week or re-occurring pruritus; grade 4 neutropenia (absolute neutropenia count $<0.5 \times 10^{9} / \mathrm{L}$ ) with a duration $\geq 5$ days, or grade 3 or 4 febrile neutropenia (temperature $\geq 38.5^{\circ} \mathrm{C}$ ); thrombocytopenia $\left(\leq 25 \times 10^{9} / \mathrm{L}\right)$, or use of blood or its component for the therapy of thrombocytopenic hemorrhage; other grade 4 hematologic toxicities or grade 3 non-hematologic toxicities.

\section{Assessment of pharmacokinetics}

Blood samples $(2 \mathrm{~mL})$ for simotinib $\mathrm{PK}$ analysis were collected on Day 1 ( $0.05 \mathrm{hrs}$ before the first dose and $0.5,1,1.5,2,4,6,8,10,12,24$ hrs after dosing); Days 8,9 and $10(0.05 \mathrm{hrs}$ before the administration of the first dose of simotinib/day); Day 15 (0.05 hr before the administration of the first dose/day, 0.5, 1, 1.5, 2, 4, 6, 8, 10, 12 hrs after dosing) and Days 22 and $29(0.05 \mathrm{hr}$ before the administration of the first dose/day). Samples were analyzed by liquid chromatography with mass spectrometry detection using multiple reaction monitoring and following a procedure previously described. ${ }^{14}$ The lower limit of quantification for simotinib was $1 \mathrm{ng} / \mathrm{mL}$. PK parameters (area under the plasma concentration-time curve from time 0 to infinity; area under the plasma concentration-time curve from time 0 to the last measured concentration $\left[\mathrm{AUC}_{0 \text {-last }}\right]$; clearance [CL]; maximum drug concentration $\left[C_{\max }\right]$; minimum drug concentration $\left[C_{\min }\right]$; terminal halflife $\left[t_{1 / 2}\right.$; time to reach the maximum concentration $\left[T_{\max }\right]$; apparent volume of distribution) were calculated from individual serum concentration-time profile of simotinib using Phoenix WinNonlin 6.0 software.

\section{Assessment of clinical antitumor activity}

Clinical antitumor activity analysis was performed in the full analysis population (which included all enrolled patients who received at least one dose of simotinib) and per-protocol population. Antitumor responses (complete and partial responses) were assessed by Response Evaluation Criteria in Solid Tumors (RECIST 1.1) using imaging techniques at Baseline, on Day 29 following the first study drug administration and every 8 weeks thereafter until disease progression, death, or study termination. Objective response rate (ORR) was calculated as the number of patients with complete or partial response denominated by the total number of patients dosed. The assessed efficacy outcomes also included progressionfree survival (PFS) and overall survival (OS). PFS was measured from the date of the first drug administration until the date of documentation of disease progression or 
death from any cause. OS was measured from the date of the first drug administration until the date of death from any cause.

\section{Statistical analysis}

Based on $3+3$ study design and dose escalation, the estimated sample size was 24-30 patients fulfilling the inclusion criteria and without any exclusion criteria. No primary statistical endpoint was used to justify this planned sample.

Statistical analysis was performed using SPSS 13.0 (SPSS Inc., Chicago, IL, USA). Safety, toxicity, PK and antitumor activity were assessed using descriptive statistics, and PFS and OS were analyzed using the KaplanMeier method.

\section{Ethics approval and informed consent}

Study protocol and all study related materials were approved by the review board of National Cancer Center/ Cancer Hospital, Chinese Academy of Medical Sciences and Peking Union Medical College Beijing, China. The study was conducted according to Good Clinical Practice Guidelines, Declaration of Helsinki, local laws and regulations. All patients provided written informed consent prior to study participation.

\section{Results}

\section{Patient characteristics}

Between April 2013 to July 2015, 41 patients fulfilling the inclusion criteria and without any exclusion criteria were enrolled and received at least one dose of simotinib. Full analysis population and safety population comprised all these 41 patients. We enrolled 28 men and 13 women with age ranging between 37 and 65 years. ECOG performance was $0-1$ in 39 patients, and 2 in 2 patients. All patients had adenocarcinoma and the majority had a TNM staging of IV. Baseline characteristics, including EGFR mutation type, are shown in Table 1. All patients harbored mutations of exons 18, 19 or 21 of EGFR. Specifically, of the 41 patients enrolled, 27 had a single 19 exon deletion, $13 \mathrm{had}$ L858R point mutation in exon 21 and 1 had an exon 18 deletion. None presented mutations in exon 20 of EGFR.

\section{Toxicity and DLT}

At least one AE was reported in 39 of the 41 enrolled patients (95.1\%) and at least one study drug-related $\mathrm{AE}$ was reported in 38 of the 41 enrolled patients $(92.7 \%)$. The most frequently
Table I Baseline patient characteristics

\begin{tabular}{|c|c|}
\hline Characteristics & Number of patients \\
\hline Enrolled & 41 \\
\hline Gender (male/female) & $28 / 13$ \\
\hline Median age (range), years & $57(37-65)$ \\
\hline \multicolumn{2}{|l|}{ ECOG PS } \\
\hline $0-1$ & 39 \\
\hline 2 & 2 \\
\hline \multicolumn{2}{|l|}{ TNM staging } \\
\hline IIIA & 1 \\
\hline IIIB & 3 \\
\hline IV & 37 \\
\hline \multicolumn{2}{|l|}{ Pathology } \\
\hline Adenocarcinoma & 41 \\
\hline \multicolumn{2}{|l|}{ EGFR gene-mutation type } \\
\hline Exon 18 & 1 \\
\hline Exon 19 & 27 \\
\hline Exon 20 & 0 \\
\hline Exon 21 & 13 \\
\hline \multicolumn{2}{|l|}{ Subgroup of EGFR mutation } \\
\hline 19-1 loss & 27 \\
\hline $2 \mathrm{I}-\mathrm{I}$ L858R & 13 \\
\hline 18 loss & I \\
\hline
\end{tabular}

Abbreviations: ECOG PS, Eastern Cooperative Group performance status; TNM, TNM staging system.

reported AEs were diarrhea and rash, reported in $56.1 \%$ and $41.5 \%$ of the participants, respectively. Other reported AEs were pruritus (reported for $24.4 \%$ of patients), neutropenia (26.8\%), anemia (22.0\%), increased level of aminotransferase (19.5\%) and bilirubin (17.1\%), and fatigue (24.4\%). AEs of grade $\geq 3$ were reported in 7 patients $(17.1 \% ; 3$ patients in the $500 \mathrm{mg}$ group and 4 patients in the dose groups below $500 \mathrm{mg}$ [ 1 per each dose group]). SAEs were reported in 2 patients (4.8\%; in $400 \mathrm{mg}$ and $500 \mathrm{mg}$ dose group, respectively); death occurred during the treatment phase in 1 patient who received $400 \mathrm{mg}$ dose. One patient (2.4\%) who received $500 \mathrm{mg}$ discontinued the study. No trend of increasing overall frequency of AEs with increasing dose of simotinib was observed (Table 2). At least 1 study drug-related AE was reported in all patients in the $100,200,300$, and $650 \mathrm{mg}$ dose groups, and in $86.7 \%$ and $91.7 \%$ of patients in the 400 and $500 \mathrm{mg}$ dose groups, respectively. With regard to specific AEs, frequencies of rash, aminotransferase elevation and fatigue were higher in patients who received 500 and $650 \mathrm{mg}$ of simotinib as compared to those who received $400 \mathrm{mg}$ simotinib. Cardiovascular toxicities were rare and reported in patients who received $\geq 400 \mathrm{mg}$ simotinib. 
Table 2 Overview of adverse events in safety population

\begin{tabular}{|c|c|c|c|c|c|c|c|}
\hline & $\begin{array}{l}100 \mathrm{mg} \\
N=2\end{array}$ & $\begin{array}{l}200 \mathrm{mg} \\
N=3\end{array}$ & $\begin{array}{l}300 \mathrm{mg} \\
\mathrm{N}=3\end{array}$ & $\begin{array}{l}400 \mathrm{mg} \\
N=15\end{array}$ & $\begin{array}{l}500 \mathrm{mg} \\
N=12\end{array}$ & $\begin{array}{l}650 \mathrm{mg} \\
N=6\end{array}$ & $\begin{array}{l}\text { Total } \\
N=41\end{array}$ \\
\hline \multicolumn{8}{|c|}{ Skin and subcutaneous tissue disorders } \\
\hline Rash, $n(\%)$ & I (50.0) & $2(66.7)$ & 0 & $2(13.3)$ & $9(75.0)$ & $3(50)$ & $17(4 \mid .5)$ \\
\hline Pruritus, $n(\%)$ & $2(100)$ & $2(66.7)$ & I (33.3) & $4(26.7)$ & I (8.3) & 0 & $10(24.4)$ \\
\hline \multicolumn{8}{|c|}{ Blood and lymphatic systems disorders } \\
\hline Neutropenia, $n(\%)$ & 0 & $3(100)$ & I (33.3) & $3(20.0)$ & $2(16.7)$ & $2(33.3)$ & II (26.8) \\
\hline Erythrocyte reduction, $n$ (\%) & 0 & I (33.3) & 0 & $4(26.7)$ & $2(16.7)$ & $2(33.3)$ & $9(22.0)$ \\
\hline \multicolumn{8}{|l|}{ Hepatobiliary disorder } \\
\hline Aminotransferase elevation, $n(\%)$ & 0 & 0 & I (33.3) & $2(13.3)$ & $2(16.7)$ & $3(50.0)$ & $8(19.5)$ \\
\hline Bilirubin elevation, $n(\%)$ & 0 & $2(66.7)$ & $2(66.7)$ & I (6.7) & $2(16.7)$ & 0 & $7(17.1)$ \\
\hline \multicolumn{8}{|l|}{ Gastrointestinal disorder } \\
\hline Diarrhea, $n$ (\%) & 0 & $3(100)$ & $3(100)$ & $7(46.7)$ & $7(58.3)$ & $3(50.0)$ & $23(56.1)$ \\
\hline \multicolumn{8}{|l|}{ General disorders } \\
\hline Fatigue, $n(\%)$ & $2(100)$ & I (33.3) & $2(66.7)$ & $2(13.3)$ & $3(25.0)$ & 0 & $10(24.4)$ \\
\hline
\end{tabular}

Abbreviations: $n / N$, number of patients; \%, percentage of patients.

None of the reported AEs fulfilled pre-set criteria for DLT for any of the doses used during dose escalation and an MTD was not reached.

\section{Pharmacokinetics}

PK parameters were calculated for all patients enrolled and are summarized in Tables 3 and 4. Single-dose PK results for the first dosing interval showed that exposure increased with dose escalation and roughly showed a linear dynamic increasing from the $100 \mathrm{mg}$ dose to the $650 \mathrm{mg}$ dose. Mean $C_{\max }$ increased from $56.5 \mathrm{ng} / \mathrm{mL}$ in the $100 \mathrm{mg}$ dose to $828.5 \mathrm{ng} /$ $\mathrm{mL}$ in the $650 \mathrm{mg}$ dose. Mean $\mathrm{AUC}_{0 \text {-last }}$ ranged between 405.6 $\mathrm{ng} \cdot \mathrm{hr} / \mathrm{mL}$ in the $100 \mathrm{mg}$ dose and $4,652.1 \mathrm{ng} \cdot \mathrm{hr} / \mathrm{mL}$ in the
$650 \mathrm{mg}$ dose. For multi-dosing, no significant differences were found for $T_{1 / 2}$ and $T_{\max }$ in sequential cohorts from 200 to $650 \mathrm{mg}$. Significant differences between doses were reported in $C_{\max }, \mathrm{AUC}_{0 \text {-last }}$ and $\mathrm{CL}$ but with no consistent doseproportional increase in exposure with increasing dose ( $P<0.05$ for all). The highest $C_{\max }$ and $\mathrm{AUC}_{0 \text {-last }}$ were observed in the $300 \mathrm{mg}$ and $500 \mathrm{mg}$ cohorts, followed by the 400 and $650 \mathrm{mg}$ cohorts. For CL, the highest value was observed in the $650 \mathrm{mg}$ cohort, followed by the 400, 500 and $200 \mathrm{mg}$ doses.

\section{Clinical antitumor activity}

By the database lock date, 40 of the 41 patients enrolled received efficacy assessment according to RECIST criteria.

Table 3 Pharmacokinetic results for single dose of simotinib

\begin{tabular}{|c|c|c|c|c|c|c|}
\hline $\begin{array}{l}\text { Parameters } \\
(\text { mean } \pm S D)\end{array}$ & $\begin{array}{l}100 \mathrm{mg} \\
\mathrm{N}=2\end{array}$ & $\begin{array}{l}200 \mathrm{mg} \\
\mathrm{N}=3\end{array}$ & $\begin{array}{l}300 \mathrm{mg} \\
\mathrm{N}=3\end{array}$ & $\begin{array}{l}400 \mathrm{mg} \\
N=15\end{array}$ & $\begin{array}{l}500 \mathrm{mg} \\
N=12\end{array}$ & $\begin{array}{l}650 \mathrm{mg} \\
N=6\end{array}$ \\
\hline$T_{1 / 2}, \mathrm{~h}$ & $5.3 \pm 0.3$ & $12.2 \pm 3.5$ & $9.2 \pm 1.0$ & $13.3 \pm 6.3$ & $28.0 \pm 33.8$ & $29.7 \pm 32.2$ \\
\hline$T_{\max }, \mathrm{h}$ & $1.8(1.5-2.0)$ & $2.0(2.0-2.0)$ & $1.5(1.5-2.0)$ & $2.0(1.0-8.0)$ & $1.8(0.5-4.0)$ & $2.0(1.0-6.0)$ \\
\hline$C_{\max }, \mathrm{ng} / \mathrm{mL}$ & $56.5 \pm 18.2$ & $333.0 \pm 35.4$ & $552.5 \pm 388.2$ & $566.4 \pm 372.0$ & $514.5 \pm 316.4$ & $828.5 \pm 849.0$ \\
\hline$A \cup C_{0 \text {-last }}, \mathrm{ng} \cdot \mathrm{hr} / \mathrm{mL}$ & $405.6 \pm 94.8$ & $2,339.6 \pm 479.9$ & $2,8 \mid 4.0 \pm 764.5$ & $3,581.9 \pm 1,868.5$ & $3,79|.0 \pm 2,74| . \mid$ & $4,652.1 \pm 3,442.1$ \\
\hline $\mathrm{AUC}_{0-\infty}, \mathrm{ng} \cdot \mathrm{hr} / \mathrm{mL}$ & $466.2 \pm 129.9$ & $2,955.0 \pm 564.0$ & $3,243.8 \pm 776.1$ & $4,962.1 \pm 3,|4| .7$ & $6,483.8 \pm 5,008.4$ & $7,648.4 \pm 3,028.7$ \\
\hline $\mathrm{CL}, \mathrm{L} / \mathrm{h}$ & $223.1 \pm 62.2$ & $68.9 \pm 13.2$ & $95.2 \pm 22.8$ & $|27.4 \pm 1| 7.6$ & $200.5 \pm 300.1$ & $97.7 \pm 39.2$ \\
\hline$V_{d}, L$ & $1,704.0 \pm 385.8$ & $1,250.1 \pm 579.7$ & $I, 286.1 \pm 438.6$ & $2,097.2 \pm 1,506.8$ & $7,166.6 \pm 12,246.1$ & $3,873.8 \pm 3,378.1$ \\
\hline
\end{tabular}

Abbreviations: $\mathrm{AUC}_{0-t}$, area under the curve from time 0 to the last measurable plasma concentration; $A \cup C_{0-\infty}$, area under the curve from time 0 to infinity; $C L$, total body clearance; $C_{\max }$, maximum plasma concentration; $T_{\max }$, time to maximum concentration; $T_{1 / 2}$, half-life; $V_{\mathrm{d}}$, volume distribution. 


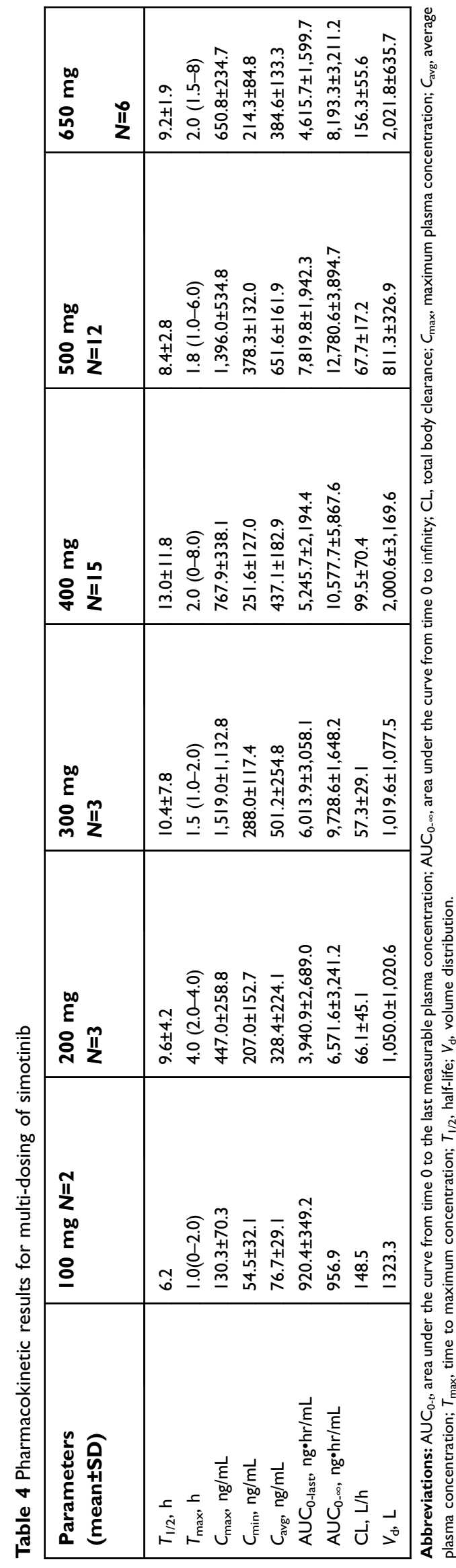

Full analysis population comprised 41 patients and perprotocol population 40 patients. Of the 41 patients enrolled, $16(39.0 \%)$ achieved a partial response and $19(46.3 \%)$ had stable disease as best response after the treatment period. Progressive disease was reported as best response for 5 patients (12.0\%). All patients with partial response or stable disease received simotinib at doses of $\geq 200 \mathrm{mg}$. In addition, 5 of the 18 patients with brain metastases achieved partial response on these metastases. Twelve patients with brain metastases received simotinib $500 \mathrm{mg}$ and partial response was achieved in $2(16.7 \%)$ of them; 6 patients with brain metastases received simotinib $650 \mathrm{mg}$ and partial response was achieved in $3(50 \%)$ of them. During the whole study (treatment phase and followup period), 7 deaths were reported: 2 in the $100 \mathrm{mg}$ group, 3 in the $200 \mathrm{mg}$ group, 1 in the $300 \mathrm{mg}$ group and 1 in the $400 \mathrm{mg}$ group. The survival rate at 1 -year was $88.2 \%$. Median PFS was 9.9 months $(95 \%$ CI: $4.7 ; 12.1)$ and median OS was 14.6 months (95\%CI: 12.3; 22.5).

Tumor lesion measurements are depicted in Figure 1. Tumor shrinkage or growth are given as percentage change from baseline tumor measurement. Tumor decrease from baseline was reported in 36 patients ( $87.8 \%$ of the patients enrolled).

\section{Discussion}

This phase Ib study showed that simotinib was well tolerated and had a favorable safety profile in patients with advanced NSCLC and EGFR mutations. No DLT was observed, and MTD was not reached at doses up to $650 \mathrm{mg}$. Skin and gastro-intestinal toxicities were the most frequently reported AEs. Most AEs were at grades $<3$, and no increase in the overall frequency of AEs with increasing doses of simotinib was observed.

The reported AEs are consistent with the known toxicity profile of other EGFR-TKIs, such as erlotinib, gefitinib, afatinib, icotinib, and cetuximab, in which rash and gastrointestinal side-effects are the most frequently reported drugrelated AEs. ${ }^{15-18}$ For example, results of clinical trials showed frequencies of diarrhea at $40.0-67.9 \%$ for erlotinib, ${ }^{19,20} 27.0-58.2 \%$ for gefitinib ${ }^{21-24}$ and $87.0 \%$ for afitinib, ${ }^{25}$ similar to that observed in this phase I study (56.1\%). Mechanisms involved in skin and gastrointestinal toxicities of EGFR-TKIs are either a reversible or an irreversible tyrosine kinase blockade. EGFR is highly expressed at epithelial level and is involved in the maintenance of mucosal and skin integrity. ${ }^{26}$ Preclinical research showed that simotinib reduces the expression of cell junction gene afadin-6, a target of EGFR/Ras/MAPK signaling 


\section{A}

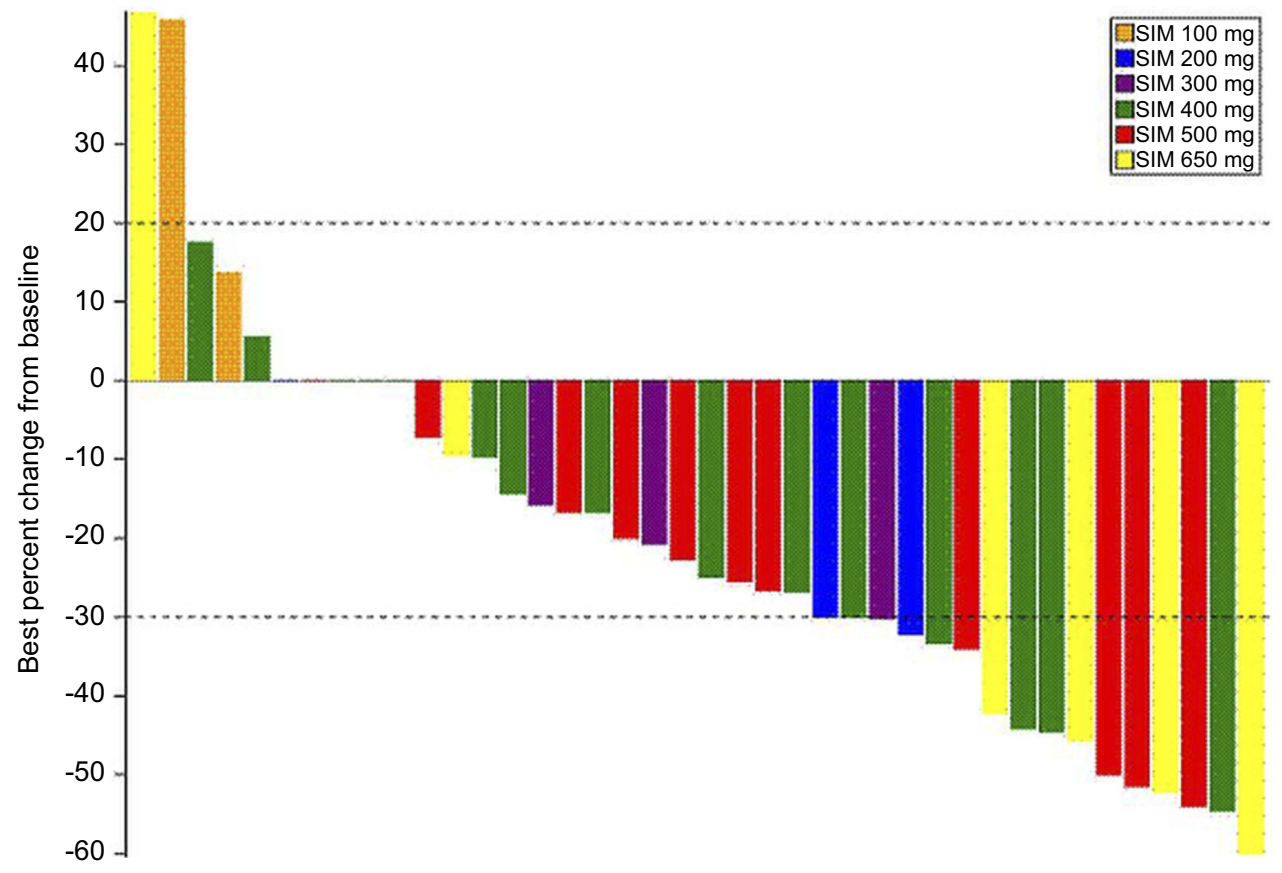

B

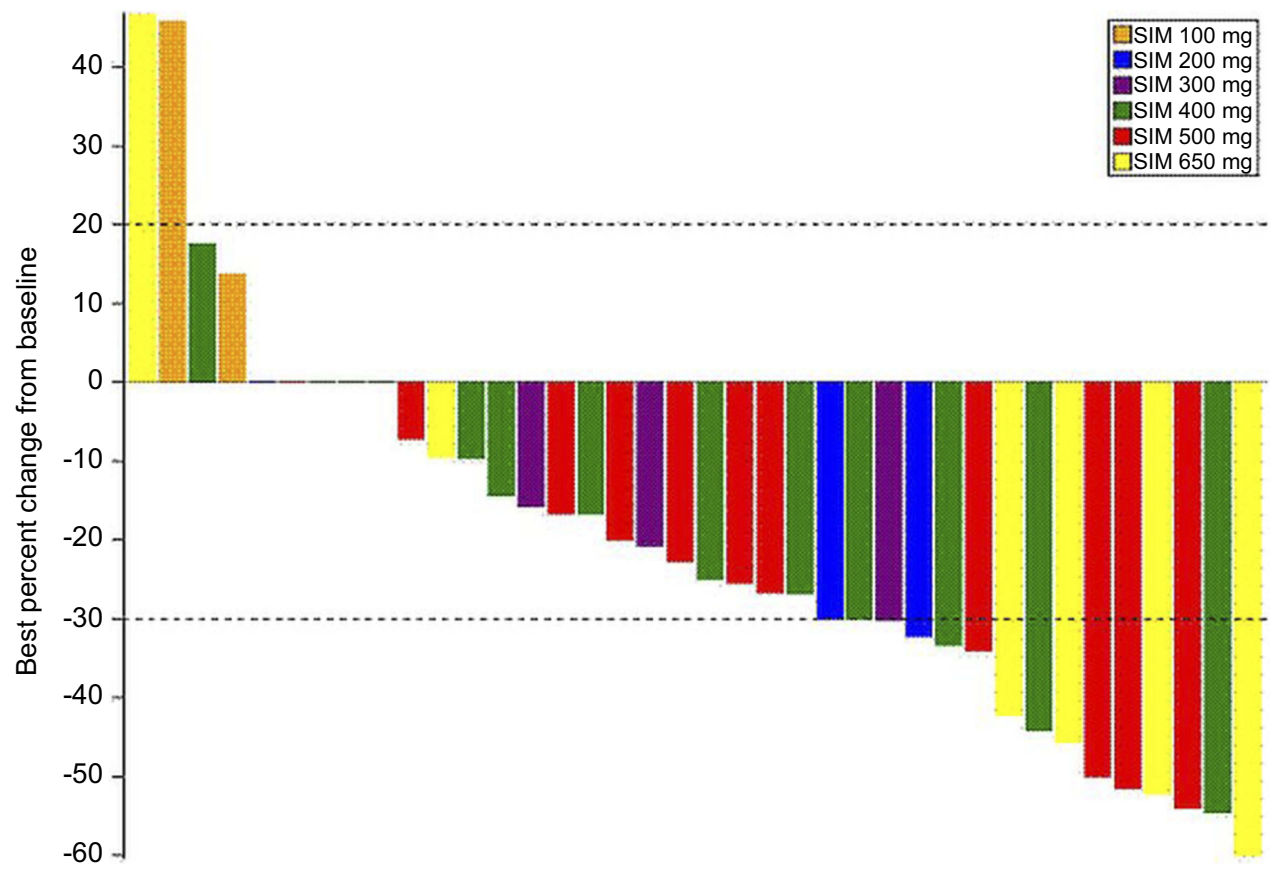

Figure I Waterfall plot of best percent change from baseline in sum of target lesion dimensions from baseline. (A) Full analysis population and (B) per protocol population ( $n=40)$.

pathway, resulting in higher paracellular permeability at the level of intestinal epithelium. ${ }^{27}$

Another frequently reported toxicity of EGFR-TKIs is hepatotoxicity. In this NLSC study, aminotransferase elevations were reported in $19.5 \%$ of all patients enrolled. It was reported only in dose cohorts of $300-650 \mathrm{mg}$, with the highest frequency in the $650 \mathrm{mg}$ cohort. Although the sample size is limited to draw a definitive conclusion, these results suggest that hepatic toxicity of simotinib is mild but may increase with increasing dose. Our results for 
simotinib are in line with previous reports on hepatotoxicity for other EGFR-TKIs in the treatment of NLSC patients. The majority of studied drugs in this class are reported to induce hepato-toxicity, ${ }^{28}$ with the all-grade hepatotoxicity frequency ranging from $<10 \%$ for gefitinib ${ }^{24}$ and erlotinib ${ }^{29}$ to $48 \%$ for gefitinib. ${ }^{30}$ Among potential causes associated with this wide range of incidences of hepatotoxicity were the differences in duration of treatment (frequency increased with exposure duration), race and potential exacerbation of preexisting liver disease. ${ }^{30}$

No cardiovascular events meeting the DLT criteria were reported in this study. Given the encouraging results, a new study exploring higher simotinib doses is ongoing and to date 3 patients have received $800 \mathrm{mg}$ simotinib and 1 received $1,000 \mathrm{mg}$ simotinib. In patients who received $800 \mathrm{mg}$ simotinib, decreased blood pressure of $<90 / 60$ $\mathrm{mmHg}$ occurred in all patients, bradycardia in 1 patient and dose reduction due to cardiovascular events in 1 patient.

The PK results showed a good bioavailability of orally administered simotinib. $C_{\max }$ following single dose PK assessment was achieved in 1.5-2.0 hrs for all doses, faster than that reported for gefitinib in cancer patients ( $3 \mathrm{hrs}$ postdose). ${ }^{31}$ Although single-dose PK analysis showed increasing exposure with dose escalation, multiple-dose PK results showed no consistent dose-proportional increase in exposure with doses over $300 \mathrm{mg}$. $C_{\max }, \mathrm{AUC}_{0 \text {-last }}$ and $\mathrm{CL}$ increased proportionally with dose up to $300 \mathrm{mg}$. From $300 \mathrm{mg}$ these parameters were significantly different among doses used but with no trend of increase with increasing dose used. $T_{\max }$ appeared to be independent of doses used. Maximum concentration was observed at 1.5 hrs after $300 \mathrm{mg}$ and at $2.0 \mathrm{hrs}$ after 200, 400, and $650 \mathrm{mg}$ in PK results for a single dose. For PK analysis after multiple dosing, maximum concentration was reached at 1.5-2.0 hrs after 300, 400, 500, and $650 \mathrm{mg}$ doses, while the lowest and the highest $T_{\max }$ were observed for the 100 and $200 \mathrm{mg}$ doses, respectively. These observations suggest considerable inter-patient variation of exposure after administration of multiple doses. This inter-patient variability was also reported for gefitinib, with a reported variability of 1.5 -fold post single-dose exposure. ${ }^{31}$ The $T_{1 / 2}$ of $8-13 \mathrm{hrs}$ for $200-650 \mathrm{mg}$ doses is consistent with our previous studies in healthy volunteers, ${ }^{12}$ suggesting that twice daily administration is appropriate.

Encouraging evidence of antitumor activity of simotinib was observed in this study. $39.3 \%$ of the patients enrolled achieved a partial response and $46.3 \%$ of the patients had stable disease with doses ranging from 200 to $650 \mathrm{mg}$.
Median PFS after a single cycle of simotinib was 9.9 months. These results are similar to those reported for gefitinib and erlotinib which ranged from 9.2 to 10.8 months in NSCLC patients with EGFR mutations. ${ }^{7,32,33}$ Additionally, we observed an objective response in the treatment of brain metastases with doses between 200 and $650 \mathrm{mg}$. There have been increased interest in exploring the potential role of EGFR-TKI agents in the treatment of NSCLC patients with brain metastases. ${ }^{34}$ It has been shown that the frequency of brain metastases is higher in NSCLC patients with EGFR mutations as compared to wild type $E G F R .{ }^{35}$ Due to blood-brain barrier, only low concentrations of cytotoxic agents can be delivered into the central nervous system. The concentration has been shown to be higher for EGFR-TKI agents, which are small molecules, and thus may cross blood-brain barrier easier and may be more effective than standard chemotherapy. ${ }^{36,37}$ It has been shown that the concentration of EGFR-TKI agents in cerebrospinal fluid increases with higher doses and increasing doses in those patients with brain metastases who did not respond to lower doses may result in disease control. ${ }^{38-40}$ Gefitinib, erlotinib and afitinib have been shown to have impressive effect on brain metastases with $60-80 \%$ response rates. ${ }^{41,42}$ In our patients we observed a similar effect - the percentage of patients with brain metastases who achieved a partial response increased with higher simotinib doses (16\% with $500 \mathrm{mg}$ simotinib and 50\% with $650 \mathrm{mg}$ ). These results are encouraging and indicate an antitumour activity of simotinib at investigated doses comparable to that reported for other EGFR-TKIs already approved. ${ }^{43}$ Given that DLT has not been observed in this study and that there was a trend in increased ORR and partial response of brain metastases with increased simotinib doses, we hypothesize that the antitumor activity of simotinib may be further improved at higher doses. Future head-to-head comparison clinical trials may be warranted to investigate whether higher simotinib doses may improve the response rate and survival of NSCLC patients with mutated $E G F R$ as compared to existing EGFR-TKIs.

The small numbers of patients enrolled in the 100, 200 and $300 \mathrm{mg}$ cohorts is a limitation of this study that we must acknowledge. This limitation was due to that nature of this early phase trial and the design chosen for this study $(3+3$ dose escalation design according to a modified Fibonacci scheme). The small numbers of patients in these groups may have influenced the frequencies of AEs reported in the 100-300 mg groups. Future trials enrolling a larger number of patients will allow 
a better characterization of the safety profile of simotinib. Also, in our study we noticed partial response or stable disease only in patients who received a simotinib dose $\geq 200 \mathrm{mg}$ and that the majority of deaths due to disease progressions occurred in the 100, 200 and $300 \mathrm{mg}$ dose groups. All these support our observations that higher simotinib doses may be associated with higher chances of achieving a stable disease or a partial response.

\section{Conclusion}

This study showed that twice-daily simotinib, a novel EGFR-TKI, has a favorable safety profile, is orally bioavailable and has good antitumor activity in advanced NSCLC patients with EGFR mutations. The safety profile and PK results were similar to those reported in healthy volunteers and in studies with other EGFR-TKIs. Studies exploring higher doses of simotinib (800 and 1,000 mg) and its use in the treatment of NSCLC patients with brain metastases are ongoing. These studies will allow a better characterization of the simotinib efficacy and safety profile and the selection of a simotinib dose with optimal benefit/ risk ratio for these patients.

\section{Abbreviation list}

$\mathrm{AE}$, adverse event; $\mathrm{AUC}_{0 \text {-last, }}$ area under the plasma concentration-time curve from time 0 to the last measured concentration; CL, clearance; $C_{\max }$, maximum drug concentration; $C_{\text {min }}$, minimum drug concentration; DLT, doselimiting toxicity; ECOG, Eastern Cooperative Oncology Group; LVEF, left ventricular ejection fraction; MTD, maximum tolerated dose; NCI CTC AE, National Cancer Institute Common Terminology Criteria for Adverse Events; NSCLC, non-small cell lung cancer; ORR, objective response rate; OS, overall survival; PFS, progressionfree survival; PK, pharmacokinetic; RECIST, Response Evaluation Criteria in Solid Tumors; SAE, serious adverse event; $T_{1 / 2}$, terminal half-life; TKI, tyrosine kinase inhibitors; $T_{\max }$, time to reach the maximum concentration.

\section{Acknowledgments}

The authors would like to thank all patients who participated in this study. The authors of the manuscript would like to acknowledge the editorial support provided by Adriana Rusu (on behalf of BC-BIOSTAT Co., Ltd) in the development of the current manuscript. This work was supported by Jiangsu Simcere Pharmaceutical Co. Ltd and grants from the Chinese National Major Project for New Drug Innovation (grant numbers 2012ZX09303012-001 and 2014ZX09304003-003-002).
The sponsor participated in the trial design and facilitated the overall operational process, including data collection and statistical analyses, documentation of trial reports. The sponsor was also involved in the decision to publish this manuscript.

\section{Author contributions}

All authors had a significant contribution to the conception and design of the study, data acquisition, or analysis and interpretation of data, drafted the article or revised it critically for important intellectual content, approved the final version to be published and accept to be accountable for all aspects of the work.

\section{Disclosure}

Dr Xing-Sheng Hu, Dr Sheng Yang, Dr Ning Li, Dr Lin Wang, Dr Yuan-Yuan Song and Dr Yuan-Kai Shi report non-financial support from Jiangsu Simcere Pharmaceutical Co. Ltd and grants from the Chinese National Major Project for New Drug Innovation during the conduct of the study. Hua $\mathrm{Mu}$ is employee of Jiangsu Simcere Pharmaceutical Co. Ltd. Dr Xiao-Hong Han reports grants from Chinese National Major Project for New Drug Innovation, during the conduct of the study; Dr Hua $\mathrm{Mu}$ reports nothing from Simcere Pharmaceutical Group, outside the submitted work. The authors report no other conflicts of interest in this work.

\section{Data availability}

Individual patient data are confidential and thus they cannot be made publicly available.

\section{References}

1. International Agency for Research on Cancer, World Health Organization. Cancer fact sheets: lung cancer. Available from: http:// gcoiarcfr/today/fact-sheets-cancers? cancer $=11 \&$ type $=0 \&$ sex $=0$. Accessed March 23, 2018.

2. Kocher F, Lunger F, Seeber A, et al. Incidental diagnosis of asymptomatic non-small-cell lung cancer: a registry-based analysis. Clin Lung Cancer. 2016;17(1):62-67.e1. doi:10.1016/j.cllc.2015.08.006

3. Walters S, Maringe C, Coleman MP, et al. Lung cancer survival and stage at diagnosis in Australia, Canada, Denmark, Norway, Sweden and the UK: a population-based study, 2004-2007. Thorax. 2013;68 (6):551-564. doi:10.1136/thoraxjnl-2012-202297

4. Kim JS, Cho MS, Nam JH, Kim HJ, Choi KW, Ryu JS. Prognostic impact of EGFR mutation in non-small-cell lung cancer patients with family history of lung cancer. PLoS One. 2017;12(5):e0177015. doi:10.1371/journal.pone.0177015

5. Wieduwilt MJ, Moasser MM. The epidermal growth factor receptor family: biology driving targeted therapeutics. Cell Mol Life Sci. 2008;65(10):1566-1584. doi:10.1007/s00018-008-7565-9

6. Werutsky G, Debiasi M, Sampaio FH, et al. P1.08: updated analysis of global epidemiology of EGFR mutation in advanced non-small cell lung cancer: track: prevention, early detection, epidemiology and tobacco control. $J$ Thorac Oncol. 2016;11(10S):S184-S185. doi:10.1016/j.jtho.2016.08.030 
7. Maemondo M, Inoue A, Kobayashi K, et al. Gefitinib or chemotherapy for non-small-cell lung cancer with mutated EGFR. $N$ Engl $J$ Med. 2010;362(25):2380-2388. doi:10.1056/NEJMoa0909530

8. Cappuzzo F, Ciuleanu T, Stelmakh L, et al. Erlotinib as maintenance treatment in advanced non-small-cell lung cancer: a multicentre, randomised, placebo-controlled phase 3 study. Lancet Oncol. 2010;11(6):521-529. doi:10.1016/S1470-2045(10)70112-1

9. Bria E, Milella M, Cuppone F, et al. Outcome of advanced NSCLC patients harboring sensitizing EGFR mutations randomized to EGFR tyrosine kinase inhibitors or chemotherapy as first-line treatment: a meta-analysis. Ann Oncol. 2011;22(10):2277-2285. doi:10.1093/ annonc/mdq731

10. Cadranel J, Mauguen A, Faller M, et al. Impact of systematic EGFR and KRAS mutation evaluation on progression-free survival and overall survival in patients with advanced non-small-cell lung cancer treated by erlotinib in a French prospective cohort (ERMETIC project-part 2). J Thorac Oncol. 2012;7(10):1490-1502. doi:10.1097/ JTO.0b013e 318265b2b5

11. Shigematsu H, Lin L, Takahashi T, et al. Clinical and biological features associated with epidermal growth factor receptor gene mutations in lung cancers. J Natl Cancer Inst. 2005;97(5):339-346. doi:10.1093/jnci/dji080

12. He L, Li S, Xie F, et al. LC-ESI-MS/MS determination of simotinib, a novel epidermal growth factor receptor tyrosine kinase inhibitor: application to a pharmacokinetic study. $J$ Chromatogr B Analyt Technol Biomed Life Sci. 2014;947-948:168-172. doi:10.1016/j. jchromb.2013.12.021

13. Kwapiszewski R, Pawlak SD, Adamkiewicz K. Anti-EGFR agents: current status, forecasts and future directions. Target Oncol. 2016;11 (6):739-752. doi:10.1007/s11523-016-0456-3

14. Li N, Han X, Du P, et al. Development and validation of a UPLC-MS/MS assay for the quantification of simotinib in human plasma. Anal Bioanal Chem. 2014;406(6):1799-1805. doi:10.1007/ s00216-013-7452-6

15. Lim SM, Cho BC, Kim SW, et al. A multicenter phase II study of sorafenib in combination with erlotinib in patients with advanced non-small cell lung cancer (KCSG-0806). Lung Cancer. 2016;93:1 -8. doi:10.1016/j.lungcan.2015.12.005

16. Gross ME, Leichman L, Lowe ES, Swaisland A, Agus DB. Safety and pharmacokinetics of high-dose gefitinib in patients with solid tumors: results of a phase I study. Cancer Chemother Pharmacol. 2012;69(1):273-280. doi:10.1007/s00280-011-1757-y

17. Liu D, Zhang L, Wu Y, et al. Clinical pharmacokinetics, safety, and preliminary efficacy evaluation of icotinib in patients with advanced non-small cell lung cancer. Lung Cancer. 2015;89(3):262-267. doi:10.1016/j.lungcan.2015.05.024

18. Ramalingam SS, Kotsakis A, Tarhini AA, et al. A multicenter phase II study of cetuximab in combination with chest radiotherapy and consolidation chemotherapy in patients with stage III non-small cell lung cancer. Lung Cancer. 2013;81(3):416-421. doi:10.1016/j. lungcan.2013.06.002

19. Shepherd FA, Rodrigues Pereira J, Ciuleanu T, et al. Erlotinib in previously treated non-small-cell lung cancer. $N$ Engl $J$ Med. 2005;353(2):123-132. doi:10.1056/NEJMoa050753

20. Gatzemeier U, Pluzanska A, Szczesna A, et al. Phase III study of erlotinib in combination with cisplatin and gemcitabine in advanced non-small-cell lung cancer: the tarceva lung cancer investigation trial. J Clin Oncol. 2007;25(12):1545-1552. doi:10.1200/JCO.2005.05.1474

21. Herbst RS, Giaccone G, Schiller JH, et al. Gefitinib in combination with paclitaxel and carboplatin in advanced non-small-cell lung cancer: a phase III trial - INTACT 2. J Clin Oncol. 2004;22(5):785-794. doi:10.1200/JCO.2004.08.040

22. Giaccone G, Herbst RS, Manegold C, et al. Gefitinib in combination with gemcitabine and cisplatin in advanced non-small-cell lung cancer: a phase III trial - INTACT 1. J Clin Oncol. 2004;22(5):777-784. doi:10.1200/JCO.2004.08.040
23. Thatcher N, Chang A, Parikh P, et al. Gefitinib plus best supportive care in previously treated patients with refractory advanced non-small-cell lung cancer: results from a randomised, placebo-controlled, multicentre study (Iressa Survival Evaluation in Lung Cancer). Lancet. 2005;366(9496):1527-1537. doi:10.1016/ S0140-6736(05)67528-9

24. Kim ES, Hirsh V, Mok T, et al. Gefitinib versus docetaxel in previously treated non-small-cell lung cancer (INTEREST): a randomised phase III trial. Lancet. 2008;372(9652):1809-1818. doi:10.1016/S0140-6736(08) 61758-4

25. Miller VA, Hirsh V, Cadranel J, et al. Afatinib versus placebo for patients with advanced, metastatic non-small-cell lung cancer after failure of erlotinib, gefitinib, or both, and one or two lines of chemotherapy (LUX-Lung 1): a phase $2 \mathrm{~b} / 3$ randomised trial. Lancet Oncol. 2012;13(5):528-538. doi:10.1016/S1470-2045(12)70140-7

26. Takeda M, Nakagawa K. Toxicity profile of epidermal growth factor receptor tyrosine kinase inhibitors in patients with epidermal growth factor receptor gene mutation-positive lung cancer. Mol Clin Oncol. 2017;6(1):3-6.

27. Zhu Q, Liu Z, Li P, Cheng Z. Drug interaction studies reveal that simotinib upregulates intestinal absorption by increasing the paracellular permeability of intestinal epithelial cells. Drug Metab Pharmacokinet. 2014;29(4):317-324. doi:10.2133/dmpk.DMPK-13RG-123

28. Shah RR, Morganroth J, Shah DR. Hepatotoxicity of tyrosine kinase inhibitors: clinical and regulatory perspectives. Drug Saf. 2013;36 (7):491-503. doi:10.1007/s40264-013-0048-4

29. Natale RB, Thongprasert S, Greco FA, et al. Phase III trial of vandetanib compared with erlotinib in patients with previously treated advanced non-small-cell lung cancer. J Clin Oncol. 2011;29 (8):1059-1066. doi:10.1200/JCO.2010.28.5981

30. Takeda M, Okamoto I, Nakagawa K. Pooled safety analysis of EGFR-TKI treatment for EGFR mutation-positive non-small cell lung cancer. Lung Cancer. 2015;88(1):74-79. doi:10.1016/j. lungcan.2015.03.006

31. Swaisland HC, Smith RP, Laight A, et al. Single-dose clinical pharmacokinetic studies of gefitinib. Clin Pharmacokinet. 2005;44 (11):1165-1177. doi:10.2165/00003088-200544110-00004

32. Mitsudomi T, Morita S, Yatabe Y, et al. Gefitinib versus cisplatin plus docetaxel in patients with non-small-cell lung cancer harbouring mutations of the epidermal growth factor receptor (WJTOG3405): an open label, randomised phase 3 trial. Lancet Oncol. 2010;11 (2):121-128. doi:10.1016/S1470-2045(09)70364-X

33. Rosell R, Carcereny E, Gervais R, et al. Erlotinib versus standard chemotherapy as first-line treatment for European patients with advanced EGFR mutation-positive non-small-cell lung cancer (EURTAC): a multicentre, open-label, randomised phase 3 trial. Lancet Oncol. 2012;13(3):239-246. doi:10.1016/S1470-2045(11) 70393-X

34. Chan BA, Hughes BG. Targeted therapy for non-small cell lung cancer: current standards and the promise of the future. Transl Lung Cancer Res. 2015;4(1):36-54.

35. Eichler AF, Kahle KT, Wang DL, et al. EGFR mutation status and survival after diagnosis of brain metastasis in nonsmall cell lung cancer. Neuro Oncol. 2010;12(11):1193-1199. doi:10.1093/neuonc/ noq076

36. Rizzi A, Tondini M, Rocco G, et al. Lung cancer with a single brain metastasis: therapeutic options. Tumori. 1990;76(6):579-581.

37. Dempke WC, Edvardsen K, Lu S, Reinmuth N, Reck M, Inoue A. Brain metastases in NSCLC - are TKIs changing the treatment strategy? Anticancer Res. 2015;35(11):5797-5806.

38. Masuda T, Hattori N, Hamada A, et al. Erlotinib efficacy and cerebrospinal fluid concentration in patients with lung adenocarcinoma developing leptomeningeal metastases during gefitinib therapy. Cancer Chemother Pharmacol. 2011;67(6):1465-1469. doi:10.1007/ s00280-011-1555-6 
39. Togashi Y, Masago K, Fukudo M, et al. Efficacy of increased-dose erlotinib for central nervous system metastases in non-small cell lung cancer patients with epidermal growth factor receptor mutation. Cancer Chemother Pharmacol. 2011;68(4):1089-1092. doi:10.1007/ s00280-011-1691-z

40. Clarke JL, Pao W, Wu N, Miller VA, Lassman AB. High dose weekly erlotinib achieves therapeutic concentrations in CSF and is effective in leptomeningeal metastases from epidermal growth factor receptor mutant lung cancer. J Neurooncol. 2010;99(2):283-286. doi:10.1007/s11060010-0128-6
41. Park SJ, Kim HT, Lee DH, et al. Efficacy of epidermal growth factor receptor tyrosine kinase inhibitors for brain metastasis in non-small cell lung cancer patients harboring either exon 19 or 21 mutation. Lung Cancer. 2012;77(3):556-560. doi:10.1016/j.lungcan.2012.05.092

42. Fan Y, Xu X, Xie C. EGFR-TKI therapy for patients with brain metastases from non-small-cell lung cancer: a pooled analysis of published data. Onco Targets Ther. 2014;7:2075-2084.

43. Sullivan I, Planchard D. Next-generation EGFR tyrosine kinase inhibitors for treating EGFR-mutant lung cancer beyond first line. Front Med (Lausanne). 2017;3:76.

\section{Publish your work in this journal}

Cancer Management and Research is an international, peer-reviewed open access journal focusing on cancer research and the optimal use of preventative and integrated treatment interventions to achieve improved outcomes, enhanced survival and quality of life for the cancer patient
The manuscript management system is completely online and includes a very quick and fair peer-review system, which is all easy to use. Visit http://www.dovepress.com/testimonials.php to read real quotes from published authors. 